\title{
Subphenotype-dependent disease markers for diagnosis and personalized treatment of autism spectrum disorders
}

\author{
Valerie W. Hu \\ Department of Biochemistry and Molecular Biology, The George Washington University, School of Medicine and \\ Health Sciences, 2300 Eye St., NW, Washington, DC 20037, USA \\ Tel.: +1 202994 8431; Fax: +1 202994 4415; E-mail: valhu@gwu.edu
}

\begin{abstract}
Autism spectrum disorders (ASD) are a collection of neurodevelopmental disorders that are currently diagnosed solely on the basis of abnormal reciprocal language and social development as well as stereotyped behaviors. Without genetic or molecular markers for screening, individuals with ASD are typically not diagnosed before the age of 2, with milder cases diagnosed much later. Because early diagnosis is tantamount to early behavioral intervention which has been shown to improve individual outcomes, an objective biomarker test that can diagnose at-risk children perinatally is a medical imperative. The rapidly increasing prevalence of ASD in the United States (now estimated at 1 in 88 individuals) also makes early diagnosis and intervention a public health imperative. This article reviews recent genome-wide (genomic) approaches to the identification of disease markers that may be used not only for diagnosis of ASD, but also for the informed development of novel drugs that target specific core symptoms of ASD. Because of the heterogeneity of clinical manifestations associated with the ASD population, this review also addresses the importance of dividing individuals with ASD into clinically relevant subphenotypes in the quest to identify appropriate biomarkers.
\end{abstract}

Keywords: Autism, clinical phenotypes, genomics, gene expression, genetics, epigenetics, gene-environment interactions

\section{Diagnosis of autism spectrum disorders}

Autism spectrum disorders (ASD) are a group of neurodevelopmental disorders that are characterized behaviorally on the basis of difficulties in initiating and maintaining reciprocal social interactions, delayed or abnormal language development and usage, and stereotyped repetitive behaviors, often with restricted interests [1]. Although recently reported to affect 1 in 88 individuals in the United States with a male-to-female ratio exceeding 4:1 [2], there are still no genetic or molecular biomarkers that can be used to unequivocally diagnose idiopathic, or nonsyndromic, ASD. This is in contrast to the genetically defined syndromic disorders, such as Fragile X, Rett, and Smith-Lemli-Opitz Syndromes, which are associated with a relatively high risk for ASD (reviewed in [3]). The difficulty in iden- tifying genes and other biological markers for ASD arises at least in part from the phenotypic diversity associated with this broad spectrum disorder, which undoubtedly is the result of multiple etiologies. Thus, a key strategy in the identification of potential biomarkers for ASD is the stratification of the population into more homogeneous clinical subgroups, each of which may reflect a shared biological phenotype. Also implicit in the design of studies to identify disease markers for ASD is the need to use non-neuronal surrogate tissues, such as blood, that can be easily accessed for diagnostic screening in the clinic. In this article, I will provide a brief overview of various methods that have been used to reduce the heterogeneity of ASD for genetic/genomic analyses, and then describe some of our recent high-throughput genomic studies on ASD subtypes that lend insight into disease markers that suggest novel subtype-dependent therapeutic options. 


\section{Parsing the broad autism spectrum into discrete phenotypes}

\subsection{Categorical vs. dimensional stratification of ASD}

Different approaches have been used to divide the ASD population into more homogeneous subgroups for genetic and other biological analyses. For example, using a categorical approach, individuals with ASD have been subdivided on the basis of regression (e.g., loss of acquired language or social skills) or early-onset for gene expression analyses of primary lymphocytes [4]. This study demonstrated that genes involved in natural killer (NK) cytotoxicity were prominent among differentially expressed genes shared by both regressive and early-onset phenotypes relative to controls from the general population. However, it was not clear what distinguished these two phenotypes from each other. Other studies utilized language phenotypes in genetic linkage analyses to highlight markers on chromosomes $7 q$ and $13 q$ [5], although these results could not be replicated in an independent study [6]. An alternative approach to heterogeneity reduction is the use of quantitative traits to stratify individuals according to symptom severity. Such dimensional stratification of subjects also permits inclusion of undiagnosed "broad spectrum" individuals (usually family members of the proband) [7, 8] who exhibit a relevant autistic trait or "endophenotype" [9], which increases the power of associating a genetic variant with a particular trait. Examples of genetic studies employing dimensional stratification include those which have used severity of language impairment [10], nonverbal communication [11], social skills $[12,13]$, insistence on sameness and repetitive behaviors [14] to identify quantitative trait loci (QTL) or single nucleotide polymorphisms (SNPs) that associate with these deficits. While improving significance (i.e., LOD or Z-scores) for specific chromosomal regions in linkage analyses, it is worth mentioning that most of the above-mentioned studies stratified individuals according to a single dimension, such as, language or social impairment.

\subsection{Multi-dimensional subphenotyping of ASD}

In order to reduce the heterogeneity within the ASD population for genome-wide gene expression analyses, we developed a novel phenotyping method involving multivariate cluster analyses of severity scores from the ADI-R diagnostic instrument [15] (widely considered to be a "gold standard" behavioral diagnostic mea- sure for ASD) to separate individuals with ASD into subgroups according to similarity of symptomatic behavioral profiles [16]. In contrast to the cited studies that divided the ASD population according to a single or a few specific traits (such as regression, repetitive behaviors, or loss of spoken words), we selected 123 item scores that captured a broad spectrum of behaviors manifested by individuals with ASD in order to identify phenotypic subgroups of individuals with idiopathic ASD on the basis of similarity of symptom severity across multiple functional domains. Moreover, the use of multiple ADI-R items for each trait (which included spoken language, nonverbal communication, social interactions, play skills, restricted interests and repetitive behaviors, sensory abnormalities, aggression, and savant skills) adds to the robustness of the cluster analyses and hence phenotype definition, since the multiplicity of items interrogating a specific trait in part buffers against inaccurate responses for any single item (e.g., due to faulty recollection or perception of the respondent). Based on hierarchical and K-means cluster analyses which were supported by unsupervised principal components analyses of the individuals based on the 123 ADI-R item scores, we could distinguish 4 phenotypes of ASD which were described according to differential severity profiles. These ASD phenotypes included: 1) a subgroup with high severity scores across all items and, most notably, language deficits, 2) a subgroup with a high frequency of savant skills, 3) a subgroup exhibiting mild severity across all ADI-R items (many in this group having a clinical diagnosis of PDD-NOS or Asperger's Syndrome), and 4) a subgroup of intermediate severity across all items, but with a low frequency of savant skills. As described below, gene expression profiling and genome-wide association (GWA) analyses demonstrated that these ASD subtypes could be associated with distinct, but somewhat overlapping transcriptomic (i.e., gene expression) and genetic signatures.

\section{Association of biological phenotypes and disease markers with ASD phenotypes}

To test the hypothesis that these ASD behavioral subphenotypes represented distinct biological phenotypes, we conducted large-scale gene expression analyses on lymphoblastoid cell lines (LCL) derived from individuals in 3 of the 4 defined ASD phenotypes: the severely language-impaired, the mild, and the "savant" subtypes [17]. The resulting gene expression profiles 


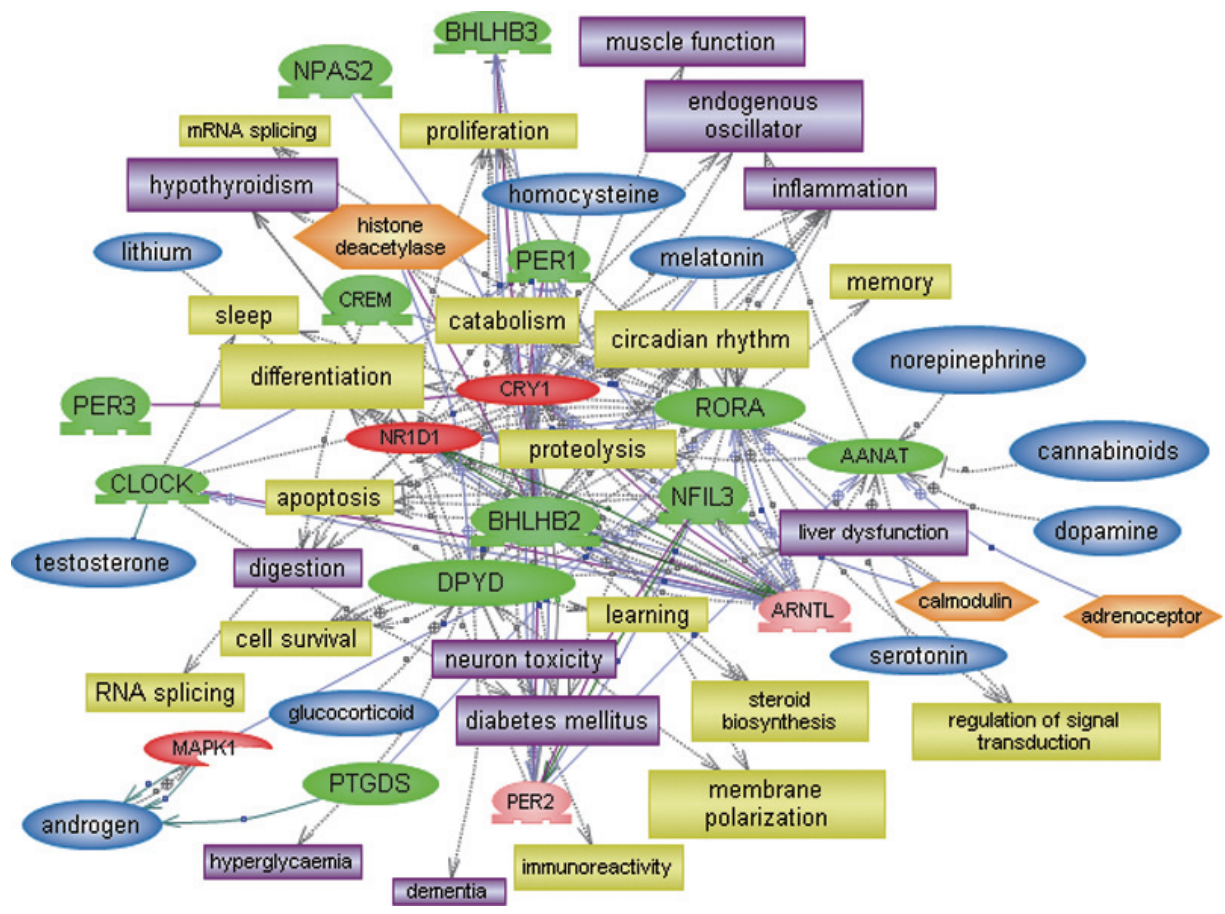

Fig. 1. An interactive gene network comprised of the 15 circadian rhythm-related genes that were differentially expressed in the subtype of ASD with severe language impairment. Pathway Studio network prediction software was used to find relationships between this set of genes and associated genes, processes, and disorders, as reported in the literature. The green entities (AANAT, BHLHB2, BHLHB3, CLOCK, CREM, DPYD, NFIL3, NPAS2, PER1, PER3, PTGDS, RORA) in the network represent genes downregulated in individuals with ASD relative to controls, whereas the red entities (CRY1, MAPK1, NR1D1) denote genes that are upregulated relative to controls. Figure reproduced from [17]. (Colours are visible in the online version of the article; http://dx.doi.org/10.3233/DMA-2012-0916)

differentiated the individuals with ASD from controls while distinguishing each ASD subtype from the others, thus associating a "biological phenotype" with a specific behavioral or symptomatic phenotype. Moreover, these subtype-dependent expression profiles were both qualitatively as well as quantitatively distinct from each other, with sets of genes being either directly or inversely correlated with severity of phenotype. Interestingly, 15 genes that are involved in, or strongly dependent on, circadian rhythm were dysregulated only in the subtype of ASD with severe language impairment. An interactive gene network constructed by pathway analysis of these 15 genes is shown in Fig. 1. As some of these genes have profound effects on sleep as well as neurological functioning, this finding suggests a treatment modality aimed at treating the sleep disorder in individuals who present with abnormal levels of key genes in this network. For example, the gene arylakylamine$\mathrm{N}$-acetyltransferase (AANAT), which produces the ratelimiting enzyme in the synthesis of the sleep-inducing hormone melatonin, is downregulated in this subtype of ASD. This finding suggests that melatonin supplementation may improve circadian rhythm as well as associ- ated neurological functions. Indeed, the interplay between synaptic function and circadian rhythm has been proposed [18]. Another gene within this network that may suggest a therapeutic option is dihydropyrimidine dehydrogenase $(D P Y D)$, which produces an enzyme whose deficiency predisposes individuals to epilepsy and mental retardation [19] which are co-morbid conditions often associated with the most severely affected individuals with ASD. It is notable that $18 \%$ of individuals with a genetic mutation in DPYD have also been diagnosed with ASD [19]. Because of the high risk for epilepsy and associated neurological problems, individuals with ASD who exhibit a reduction in DPYD may be most responsive to anti-convulsant medications. Thus, AANAT and DYPD are examples of disease markers that may potentially serve as both diagnostic as well as therapeutic targets for the most severe subtype of ASD, especially if these enzymes are found to be reduced in the affected individuals. As will be discussed later, retinoic acid-related orphan receptor-alpha (RORA), another circadian regulator gene within this network, may also serve as a sentinel for environmental triggers of ASD. 


\section{Genetics: A search for causal mutations and disease markers in DNA}

\subsection{Genome-wide approaches to identify linkage regions and genetic variants}

Although autism spectrum disorders exhibit a strong genetic component, it has been difficult to identify causal mutations or even robust genetic biomarkers through classical genetics methodologies, including cytogenetic analyses, linkage disequilibrium family studies on suspected chromosomal regions, and candidate gene association analyses. As such studies have been extensively reviewed elsewhere [20-24], they will not be addressed here, inasmuch as the focus of this review is on the use of genome-wide or '-omics' approaches to identify disease markers of ASD.

Recently, large-scale genotyping techniques using microarrays have made possible the genome-wide analyses of genetic variation in hundreds to thousands of individuals in both genetic linkage studies (using pedigree information) as well as case-control association analyses [25-30]. These studies have revealed genetic susceptibility loci as well as candidate genes in almost every chromosome. However, many of the candidate genes from one study are not replicated in another study with a few exceptions, for example, contactinassociated protein-like 2 (CNTNAP2) which was simultaneously reported as a candidate gene for ASD by several groups [31-33]. This lack of reproducibility may be attributed in part to the genetic heterogeneity among the cases, inasmuch as most case-control studies combine individuals with ASD into one case group. In addition, the corrections for multiple testing required of genome-wide association analyses due to the sheer number of single nucleotide polymorphisms (SNPs) analyzed in any one study (from $10 \mathrm{~K}$ to now over 1 million) make it difficult to identify statistically significant SNPs. Nevertheless, integration of the findings from multiple large-scale genetic analyses points to recurrent functional themes among the candidate genes, including axon migration and synapse formation/regulation (reviewed by $[34,35]$ ).

\subsection{Linking genotype to phenotype}

To test the hypothesis that division of ASD cases into more homogeneous subtypes might also aid in the identification of significant SNPs in genome-wide association (GWA) analyses, we undertook a meta-analysis of published GWA data in which individuals with ASD were subgrouped according to ADI-R symptom severity profiles [36]. GWA data was derived from the study of Wang et al. [30] and ADI-R scoresheets for a subset of the genotyped individuals were obtained through the Autism Genetic Resource Exchange (courtesy of Dr. Vlad Kustanovich). The item scores from the ADI-R diagnostic measures were used in two ways: 1) to perform quantitative trait association analyses for 5 distinct autistic traits; and 2) to subtype individuals with ASD according to our published cluster analyses of ADI-R scores [16]. For quantitative trait association analyses, 14-23 ADI-R scores were summed to obtain each individual's cumulative score for each of the following 5 traits: language impairment, nonverbal communication, play skills, insistence on sameness and ritualistic behavior, and social development. We then conducted quantitative trait association analyses using the distribution of scores for each of the traits and the respective genotype data to identify sets of SNPs that are potentially of functional relevance with regard to the ASD traits. These 5 analyses together resulted in the identification of 167 unique SNPs out of the 513,312 SNPs on the array that survived quality control tests. These traitfiltered SNPs were then used in case-control association analyses in which the cases were either combined or divided into ASD subtypes as defined by our ADI-R cluster analyses. Notably, 18 novel highly significant SNPs (Bonferroni corrected $\mathrm{p} \leqslant 0.05$ ) were found to be associated with at least one of the 4 subphenotypes of ASD, while 10 of these SNPs were replicated in a second ASD subtype (representing an independent cohort), but at a lower level of significance $(<10 \%$ False Discovery Rate by Benjamini-Hochberg correction for multiple testing). Interestingly, the odds ratios (reflecting minor allele frequencies) of the replicated SNPs were distinctly different for the ASD subtypes sharing them, confirming the genetic heterogeneity between the subtypes. It is noteworthy that no significant SNPs were identified when all 1867 cases were combined and analyzed against 2438 nonautistic controls, thus underscoring the importance of ASD subtyping to identifying genotype-phenotype associations.

\subsection{Connecting SNPs to pathobiology of ASD and potential therapies}

Although all 18 of the ASD-associated SNPs are located in noncoding regions (that is, promoter, intronic and intergenic regions), some of the genes associated with the identified SNPs offer new insight into the pathobiology of ASD as well as novel therapeutic tar- 
gets [36]. One of these genes, 5-hydroxytryptamine receptor 4 (HTR4), is a serotonin receptor subtype that is present not only in the central nervous system, but also in the gastrointestinal (GI) system, where it has been associated with irritable bowel disease and other GI disorders [37]. The odds ratio for the SNP rs7725785 at the intron boundary of HTR4 is 1.44 for the severe ASD phenotype while the odds ratio is $\sim 0.7$ for both the mild and moderate phenotypes. This geneticallydefined difference in susceptibility is corroborated by separate studies involving gene expression profiling of lymphoblastoid cell lines (LCL) from these three ASD subtypes in which the expression of HTR4 was downregulated in the language-impaired group, but not in the mild or moderate subgroups [17]. This corroboration suggests a functional connection between this intronic SNP and gene expression, and provides independent support for the differential subtype-dependent involvement of HTR4 in ASD. Inasmuch as many individuals with ASDs are also affected by digestive disorders [38, 39 ], it is conceivable that drugs targeting HTR4 in the gut may improve both the GI as well as neurological symptoms associated with this ASD subtype. It is notable that two of the other significant SNPs are in the promoter regions of the chemokines CCL2O and CCL25 which, when elevated, are linked to irritable bowel disease [40]. These genes may thus serve as additional targets for the treatment of individuals with ASD who also present with comorbid GI disorders.

Another candidate gene implicated by our subphenotype-dependent GWA study is GTP cyclohydrolase I $(G C H 1)$, which lies just downstream of the SNP rs17738966 (odds ratio $=1.52$ for the moderate ASD subtype). GCH1 is the rate-limiting enzyme in the de novo biosynthesis of tetrahydrobiopterin (BH4), a cofactor required for the biosynthesis of folate, serotonin, dopamine, melatonin, and catecholamines, which are all important for neural development and functions. Indeed, reduced $\mathrm{BH} 4$ has been observed in the cerebrospinal fluid of individuals with ASD [41], and there are ongoing clinical trials using $\mathrm{BH} 4$ supplementation to address this deficiency [42]. While one clinical trial is based on evidence of pterin deficiency, the other is being conducted using a double-blind, placebo-controlled protocol. It is suggested that inclusion of genotype information regarding this SNP as a disease marker may help to identify those individuals who may benefit from such therapy. Our subtype-dependent genetic association analyses thus link common genetic variants to biological phenotypes and establish a foundation for the development of diagnostic screens as well as pharmacogenomic studies based on ASD subtype-dependent genetic markers [43].

\section{Mining the epigenome for disease markers}

\subsection{Epigenetic regulation of gene expression}

While the majority of studies directed towards identifying disease markers for ASD have focused on genetics and, to a lesser extent, gene expression, relatively few have searched for disease signatures in the epigenome. The "epigenome" is the net result of all of the epigenetic processes that regulate gene expression without altering DNA sequence. These epigenetic processes include reversible covalent modification of DNA (e.g., methylation of cytosine) and chromatin (e.g., histone acetylation, methylation, and phosphorylation) as well as the gene regulatory activities of noncoding RNA [44-48]. Epigenetic mechanisms thus act as interpreters of genetic information, receiving guidance from both internal (e.g., physiological) as well as external (e.g., environmental) signals to control the levels of gene activity. As mentioned in the previous section, all of the highly significant SNPs identified in our ASD subtype-dependent GWA analysis were in noncoding regions of the DNA. If functional, these noncoding SNPs may therefore play a role in the regulation of their host or proximal gene, as suggested by the SNP at the intron boundary of HTR 4 whose expression is reduced in the severe ASD phenotype. Alternatively, these SNPs may exert more long-range gene regulatory effects by altering chromatin structure or by mutating noncoding RNA (ncRNA) transcripts, each of which can potentially regulate hundreds of genes, even distally. A recent example of such long-range effects is the regulation of the gene moesin on chromosome $\mathrm{X}$ by an antisense ncRNA located in an intergenic region on chromosome 5p14.1 [49], which was associated with highly significant SNPs identified by a prior GWA study [30].

\subsection{The potential of ncRNAs as biomarkers for ASD}

Among the various species of gene regulatory ncRNAs, microRNA (miRNA) is the best understood with respect to mechanism of action and target gene selection. MiRNAs are endogenous, single-stranded RNA molecules of approximately 22 nucleotides in length that negatively regulate gene expression at both transcriptional and post-transcriptional levels [50]. There is ample evidence that miRNAs are involved in the development and function of the nervous system [51-54]. To date, only four studies have addressed miRNA expression in ASD. Abu-Elneel and colleagues first re- 
ported differential expression of 28 miRNAs in cerebellar tissues from 13 autistic and 13 age-, gender, PMI (post-mortem index)- and hemisphere-matched controls [55], while Talebizadeh et al. profiled miRNA expression in LCL from 6 individuals with ASD and 6 age- and sex-matched individuals [56]. The latter study reported 9 differentially expressed miRNAs between the individuals with ASD and controls, with 4 out of the 9 miRNAs overlapping with those identified by the former study, indicating that differentially expressed brain-related miRNAs can also be differentially expressed in LCL. While neither study included miRNA target validation, the majority of the differentially expressed miRNAs have predicted gene targets that had been previously identified as candidate genes for ASD through genetic analyses.

Two subsequent studies coupled miRNA expression profiling with gene expression profiling in LCL from the same samples. In a study by Sarachana et al. [57], 43 differentially expressed miRNAs, 16 of which had been previously reported to be brain-specific, brainrelated, or involved in neural differentiation [58-61], were identified between diagnostically discordant pairs of twins and siblings. The putative gene targets [inhibitor of DNA binding-3 (ID3) and polo-like kinase2 (PLK2)] of two RT-qPCR-confirmed brain-specific miRNAs [hsa-miR-29b and hsa-miR-219-5p], were validated by miRNA overexpression and knockdown assays, respectively. Moreover, the expression levels of ID3 and PLK2 and their endogenous regulatory miRNAs in the majority of LCL from cases and controls show an inverse relationship, further suggesting that ID3 and PLK2 are in vivo targets of miR29b and miR219-5p, respectively. While ID3 is involved in inhibiting neuronal differentiation and maintaining the neural stem cell pool [62,63], PLK2 is critical for nerve growth factor-induced neuronal differentiation [64] and homeostatic synaptic plasticity [65]. It is noted that the decrease in ID3 expression with a concomitant increase in PLK2 expression, as seen in individuals with ASD, would shift the balance towards depletion of neural stem cells and increased neuronal differentiation. Functional analysis of all of the predicted gene targets whose transcripts were found to show an inverse relationship with the differentially expressed miRNAs further identified gene networks involved in embryonic development, synaptic development and function, circadian rhythm signaling, inflammation, androgen metabolism, and digestive functions, all of which have been implicated in ASD. Using a similar strategy of integrating miRNA and mRNA expression in LCL de- rived from case-control siblings, Ghahramani Seno et al. reported 12 miRNAs that were differentially expressed by $\geqslant 1.5$-fold in at least 12 out of 24 sib-pair comparisons [66]. Although there was some overlap of differentially expressed miRNAs among the 4 studies, there was no consistent pattern of miRNA expression. Most likely, this inconsistency is in part due to the phenotypic heterogeneity of the cases employed in the different studies. In support of this interpretation, significant improvements in p-values for differentially expressed miRNAs were achieved (almost 7 orders of magnitude for miR486-5p) when cases that were clustered according to similarity of mRNA expression profiles were used as a separate cohort. Moreover, the reanalysis of the miRNA expression data for this cohort yielded seven additional miRNAs among the 13 most significant differentially expressed miRNAs. Thus, this study further demonstrates the added value of subtyping subjects (in this case by gene expression profiles) for large-scale genomic analyses.

With respect to the potential use of miRNAs for diagnosis of ASD, Sarachana et al. demonstrated complete separation of cases and controls by unsupervised hierarchical clustering and principal components analysis based on the 43 differentially expressed miRNAs [57]. Because of the stability of cell-released circulating miRNA molecules in plasma and serum $[67,68]$, miRNA profiles are particularly attractive candidates for biomarkers that may be detectable in easily accessed peripheral tissues (e.g., blood). However, additional studies are needed on larger and more homogeneous subgroups of cases to replicate these findings and to fully validate the usefulness of differentially expressed miRNAs as disease markers for ASD.

\section{The convergence of genomics, epigenetics, and environment on RORA, a functionally relevant biomarker for ASD}

As mentioned above, DNA methylation is another epigenetic mechanism that regulates gene expression. Although aberrant methylation has long been associated with syndromic disorders that may be comorbid with ASD, such as Fragile X, Rett Syndrome, and the imprinting disorders Angelman and Praeder-Willi Syndromes (see review of "epigenetic syndromes" by Grafodatskaya et al. [69]), relatively few studies have directly addressed the involvement of methylation in idiopathic autism. 


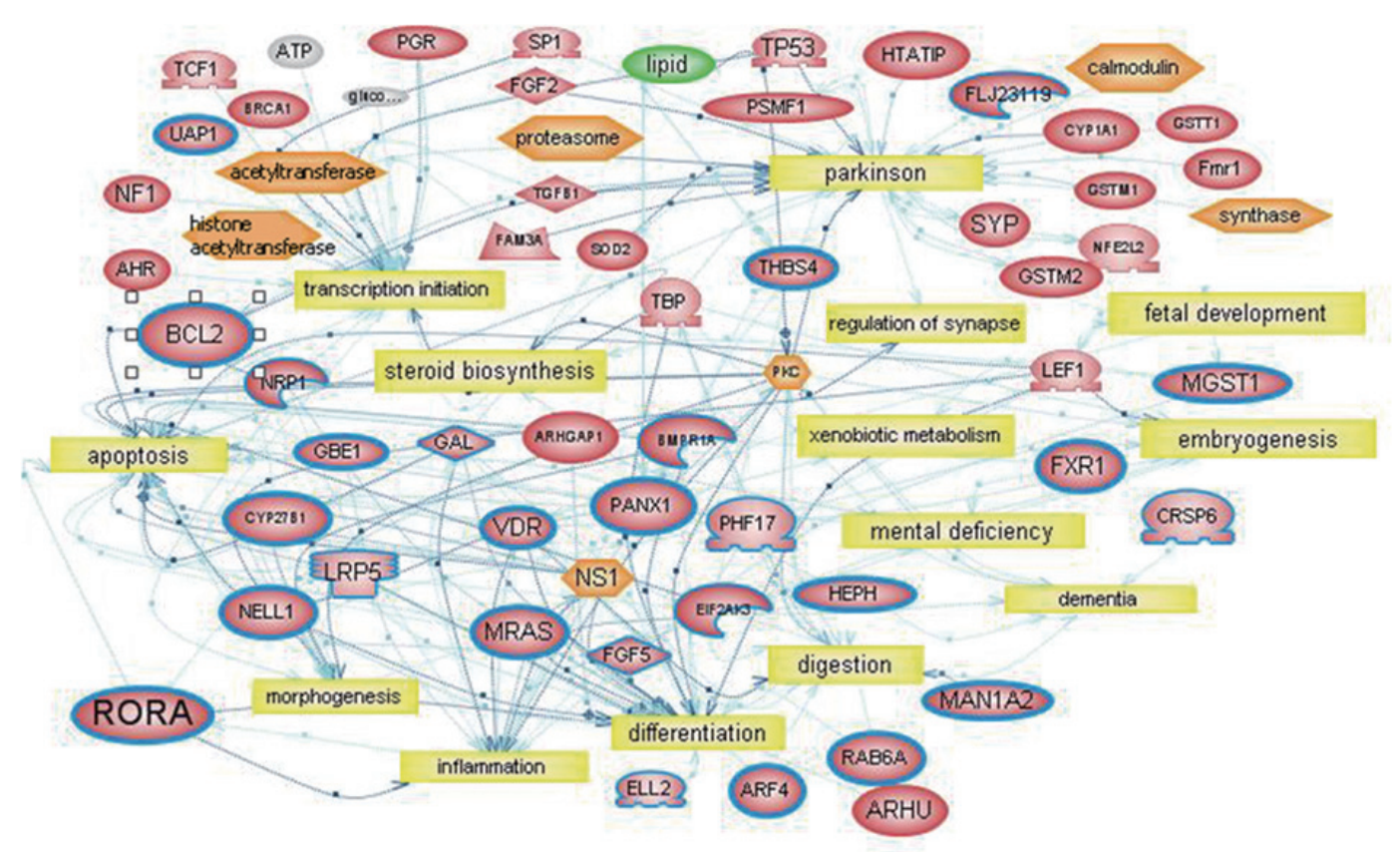

\section{Network of differentially methylated and differentially expressed genes}

Fig. 2. An interactive gene network, generated by Pathway Studio analysis, comprised of the genes (outlined in bold or blue) that exhibited both increased methylation and decreased expression from global analyses of DNA methylation and gene expression, respectively, in LCL from pairs of diagnostically discordant twins and siblings. Note the presence of RORA in this network as well as that shown in Figure 1. RORA expression was found to be reduced in 4 separate cohorts of individuals with ASD on the basis of transcript or protein levels in LCL and brain tissues, respectively. Figure reproduced from [70]. (Colours are visible in the online version of the article; http://dx.doi.org/10.3233/DMA-2012-0916)

Because little was known about specific genes that are differentially methylated in ASD, Nguyen et al. used an unbiased approach to investigate DNA methylation differences in LCL from discordant twin and sib pairs, where one individual of each pair had been diagnosed with idiopathic ASD [70]. Global methylation was assessed using an $8 \mathrm{~K} \mathrm{CpG}$ island array and the resulting data was compared against previously obtained gene expression data [71,72] for the same samples. Functional analysis of genes that exhibited both increased methylation and decreased expression revealed a gene interaction network that included ASD-relevant processes, such as fetal development, regulation of synapse, mental deficiency, inflammation, digestion, and steroid biosynthesis (Fig. 2). Two genes from the network, BCL2 and RORA, were further confirmed with respect to increased methylation and decreased expression. Moreover, the protein products of both genes were found to be reduced in post-mortem brain tissues from individuals with ASD relative to controls, thus linking molecular changes in peripheral tissuederived cells to parallel molecular changes in the autistic brain. Reduction of BCL2 protein in post-mortem brain tissues from individuals with ASD is consistent with earlier findings of reduced BCL2 in the cerebellum and frontal cortex of affected individuals [73,74]. $R O R A$, on the other hand, is a novel candidate gene for ASD that functions as a nuclear hormone receptor whose deficiency or disruption can severely impact functions known to be impaired in ASD. As determined by studies on the Rora-deficient staggerer mouse model, these functions include cerebellar development [75, 76], Purkinje cell differentiation and survival [77], neuroprotection against oxidative stress [78] and inflammation [79], and regulation of circadian rhythm [80]. Behavioral studies on the staggerer mouse, primarily used as a model to study ataxia and dystonia [75], show that Rora is also associated with restricted behaviors reminiscent of ASD, such as perseverative tendencies [81], limited maze patrolling [82], anomalous object exploration [83] as well as deficits in spatial learning [84]. Thus, Rora deficiency in mice is not only related to the pathobiology often seen in ASD, but is also associated with many of the behavioral phenotypes of ASD.

Purkinje cell loss in male staggerer mice occurs much earlier in life in comparison to cell loss in female staggerer mice [85], suggesting the possible interaction of RORA with sex-determining hormones. Sarachana 
et al. therefore investigated the influence of sex hormones on the expression of RORA in a human neuronal cell line [86]. They found that RORA expression is regulated by both male and female hormones, but in opposite directions, with the androgen dihydrotestosterone reducing RORA expression and estradiol increasing it. RORA, in turn, was demonstrated to transcriptionally regulate aromatase, an enzyme that converts testosterone to estrogen. Interestingly, both RORA and aromatase proteins were found to be reduced in the postmortem frontal cortex of individuals with ASD, with a correlation coefficient of 0.91 . These findings thus suggest an inhibitory feedback loop in which RORA deficiency can lead to elevated testosterone levels (due to reduction in aromatase) which may further suppress RORA expression. It is noteworthy that elevated fetal and serum testosterone levels have been associated with autistic traits [87-89] as well as abnormalities in brain structure [90]. Thus, we propose that females, with inherently lower testosterone levels, may exhibit a higher threshold for autism risk in response to RORA deficiency. Indeed, preliminary studies using confocal immunofluorescence analyses indicate that RORA protein levels are $\sim 17-25 \%$ higher in the frontal cortex of unaffected females relative to that of unaffected males (unpublished data), suggesting sexual dimorphism with respect to RORA expression.

Collectively, these studies suggest that RORA deficiency may contribute to the known pathophysiology, behaviors, and sex bias of ASD. The hormone sensitivity of RORA further suggests that environmental pollutants such as endocrine disrupting chemicals (EDC), many of which mimic sex hormones or their antagonists, may interfere with the normal expression and function of this critical transcriptional regulator, thus increasing risk for ASD through gene by environment interactions. Preliminary studies in our laboratory have shown that RORA expression in a neuronal cell line is indeed modulated by exposure to EDCs (unpublished data). Thus, RORA deficiency may be useful not only as a biomarker for diagnosis of the most severe subtype of ASD (i.e., with language impairment), but also as a molecular sentinel for detection of environmental health hazards that increase risk for ASD.

\section{Summary}

With the rising prevalence of ASD in the United States and the world, the identification of disease markers for the diagnosis of ASD is of utmost importance to permit early intervention which, in the absence of targeted medications, has been shown to most improve individual outcomes. As reviewed in this article, many different genome-wide approaches have been used to seek out genetic, gene expression, and epigenetic signatures of this enigmatic set of neurodevelopmental disorders. However, the heterogeneity of ASD has complicated the identification of reliably robust biomarkers that can be used for diagnostic screening. I have given a few examples in which subtyping of ASD improves the ability to identify functionally relevant disease markers. Additional advances in this area will therefore be dependent on connecting specific phenotypes of ASD with their respective underlying biological and genetic vulnerabilities. Such information will be useful not only in the molecular diagnosis of ASD, but also in the development of targeted therapies to address the specific biological deficits manifested in clinically relevant subgroups of individuals with ASD.

\section{Acknowledgements}

The work that is described from the author's laboratory was supported by grants from NIMH (R21 MH073393) and Autism Speaks (\#2381).

\section{References}

[1] American Psychological Association, Diagnostic and Statistical Manual of Mental Disorders, American Psychological Association, Washington, DC, 1994.

[2] Centers for Disease Control and Prevention, Prevalence of autism spectrum disorders - Autism and developmental disabilities monitoring network, 14 sites, United States, 2008, MMWR Surveillance Summaries 61(ss03) (2012), 1-19.

[3] A. Benvenuto, B. Manzi, R. Alessandrelli, C. Galasso and P. Curatolo, Recent advances in the pathogenesis of syndromic autisms, International Journal of Pediatrics 2009 (2009).

[4] J.P. Gregg, L. Lit, C.A. Baron, I. Hertz-Picciotto, W. Walker, R.A. Davis, L.A. Croen, S. Ozonoff, R. Hansen, I.N. Pessah and F.R. Sharp, Gene expression changes in children with autism, Genomics 91 (2008), 22-29.

[5] Y. Bradford, J. Haines, H. Hutcheson, M. Gardiner, T. Braun, V. Sheffield, T. Cassavant, W. Huang, K. Wang, V. Vieland, S. Folstein, S. Santangelo and J. Piven, Incorporating language phenotypes strengthens evidence of linkage to autism, American Journal of Medical Genetics - Neuropsychiatric Genetics 105 (2001), 539-547.

[6] S.J. Spence, R.M. Cantor, L. Chung, S. Kim, D.H. Geschwind and M. Alarcon, Stratification based on language-related endophenotypes in autism: attempt to replicate reported linkage, Am J Med Genet B Neuropsychiatr Genet 141 (2006), 591-8.

[7] J. Piven, The broad autism phenotype: A complementary strategy for molecular genetic studies of autism, American Journal of Medical Genetics 105 (2001), 34-35. 
[8] A. Bailey and J. Parr, Implications of the broader phenotype for concepts of autism, Novartis Found Symp 251 (2003), 2635; discussion 36-47, 109-11, 281-97.

[9] I.I. Gottesman and T.D. Gould, The endophenotype concept in psychiatry: Etymology and strategic intentions, American Journal of Psychiatry 160 (2003), 636-645.

[10] M. Alarcon, A.L. Yonan, T.C. Gilliam, R.M. Cantor and D.H. Geschwind, Quantitative genome scan and Ordered-Subsets Analysis of autism endophenotypes support language QTLs, Mol Psychiatry 10 (2005), 747-57.

[11] G.K. Chen, N. Kono, D.H. Geschwind and R.M. Cantor, Quantitative trait locus analysis of nonverbal communication in autism spectrum disorder, Mol Psychiatry 11 (2006), 214-20.

[12] J.A. Duvall, A. Lu, R.M. Cantor, R.D. Todd, J.N. Constantino and D.H. Geschwind, A quantitative trait locus analysis of social responsiveness in multiplex autism families, Am J Psychiatry 164 (2007), 656-62.

[13] H. Coon, M. Villalobos, R. Robison, N. Camp, D. Cannon, K. Allen-Brady, J. Miller and W. McMahon, Genome-wide linkage using the social responsiveness Scale in Utah autism pedigrees, Molecular Autism 1 (2010).

[14] D. Cannon, J. Miller, R. Robison, M. Villalobos, N. Wahmhoff, K. Allen-Brady, W. McMahon and H. Coon, Genomewide linkage analyses of two repetitive behavior phenotypes in Utah pedigrees with autism spectrum disorders, Molecular Autism 1 (2010).

[15] C. Lord, M. Rutter and A.L. Couteur, Autism diagnostic interview-revised: A revised version of a diagnostic interview for caregivers of individuals with possible pervasive developmental disorders, Journal of Autism and Developmental Disorders 24 (1994), 659-685.

[16] V.W. Hu and M.E. Steinberg, Novel clustering of items from the Autism Diagnostic Interview-Revised to define phenotypes within autism spectrum disorders, Autism research: Official Journal of the International Society for Autism Research 2 (2009), 67-77.

[17] V.W. Hu, T. Sarachana, K.S. Kim, A. Nguyen, S. Kulkarni, M.E. Steinberg, T. Luu, Y. Lai and N.H. Lee, Gene expression profiling differentiates autism case-controls and phenotypic variants of autism spectrum disorders: Evidence for circadian rhythm dysfunction in severe autism, Autism research: Official Journal of the International Society for Autism Research $\mathbf{2}$ (2009), 78-97.

[18] T. Bourgeron, The possible interplay of synaptic and clock genes in autism spectrum disorders, Cold Spring Harbor symposia on quantitative biology 72 (2007), 645-654.

[19] A.B.P. Van Kuilenburg, P. Vreken, N.G.G.M. Abeling, H.D. Bakker, R. Meinsma, H. Van Lenthe, R.A. De Abreu, J.A.M. Smeitink, H. Kayserili, M.Y. Apak, E. Christensen, I. Holopainen, K. Pulkki, D. Riva, G. Botteon, E. Holme, M. Tulinius, W.J. Kleijer, F.A. Beemer, M. Duran, K.E. NiezenKoning, G.P.A. Smit, C. Jakobs, L.M.E. Smit, U. Moog, L.J.M. Spaapen and A.H. Van Gennip, Genotype and phenotype in patients with dihydropyrimidine dehydrogenase deficiency, Human Genetics 104 (1999), 1-9.

[20] C.M. Freitag, W. Staal, S.M. Klauck, E. Duketis and R. Waltes, Genetics of autistic disorders: Review and clinical implications, European Child and Adolescent Psychiatry 19 (2010), 169-178.

[21] A.R. Gupta and M.W. State, Recent advances in the genetics of autism, Biol Psychiatry 61 (2007), 429-37.

[22] R. Muhle, S.V. Trentacoste and I. Rapin, The genetics of autism, Pediatrics 113 (2004), e472-86.
[23] F. Polleux and J.M. Lauder, Toward a developmental neurobiology of autism, Ment Retard Dev Disabil Res Rev 10 (2004), 303-17.

[24] S.L. Santangelo and K. Tsatsanis, What is known about autism: Genes, brain, and behavior, Am J Pharmacogenomics 5 (2005), 71-92.

[25] M. Bucan, B.S. Abrahams, K. Wang, J.T. Glessner, E.I. Herman, L.I. Sonnenblick, A.I. Alvarez Retuerto, M. Imielinski, D. Hadley, J.P. Bradfield, C. Kim, N.B. Gidaya, I. Lindquist, T. Hutman, M. Sigman, V. Kustanovich, C.M. Lajonchere, A. Singleton, J. Kim, T.H. Wassink, W.M. McMahon, T. Owley, J.A. Sweeney, H. Coon, J.I. Nurnberger Jr., M. Li, R.M. Cantor, N.J. Minshew, J.S. Sutcliffe, E.H. Cook, G. Dawson, J.D. Buxbaum, S.F.A. Grant, G.D. Schellenberg, D.H. Geschwind and H. Hakonarson, Genome-wide analyses of exonic copy number variants in a family-based study point to novel autism susceptibility genes, PLoS Genetics 5 (2009).

[26] J.T. Glessner, K. Wang, G. Cai, O. Korvatska, C.E. Kim, S. Wood, H. Zhang, A. Estes, C.W. Brune, J.P. Bradfield, M. Imielinski, E.C. Frackelton, J. Reichert, E.L. Crawford, J. Munson, P.M.A. Sleiman, R. Chiavacci, K. Annaiah, K. Thomas, C. Hou, W. Glaberson, J. Flory, F. Otieno, M. Garris, L. Soorya, L. Klei, J. Piven, K.J. Meyer, E. Anagnostou, T. Sakurai, R.M. Game, D.S. Rudd, D. Zurawiecki, C.J. McDougle, L.K. Davis, J. Miller, D.J. Posey, S. Michaels, A. Kolevzon, J.M. Silverman, R. Bernier, S.E. Levy, R.T. Schultz, G. Dawson, T. Owley, W.M. McMahon, T.H. Wassink, J.A. Sweeney, J.I. Nurnberger, H. Coon, J.S. Sutcliffe, N.J. Minshew, S.F.A. Grant, M. Bucan, E.H. Cook, J.D. Buxbaum, B. Devlin, G.D. Schellenberg and H. Hakonarson, Autism genome-wide copy number variation reveals ubiquitin and neuronal genes, Nature 459 (2009), 569-572.

[27] J. Sebat, B. Lakshmi, D. Malhotra, J. Troge, C. Lese-Martin, T. Walsh, B. Yamrom, S. Yoon, A. Krasnitz, J. Kendall, A. Leotta, D. Pai, R. Zhang, Y.H. Lee, J. Hicks, S.J. Spence, A.T. Lee, K. Puura, T. Lehtimaki, D. Ledbetter, P.K. Gregersen, J. Bregman, J.S. Sutcliffe, V. Jobanputra, W. Chung, D. Warburton, M.C. King, D. Skuse, D.H. Geschwind, T.C. Gilliam, K. Ye and M. Wigler, Strong association of de novo copy number mutations with autism, Science 316 (2007), 445-9.

[28] L.A. Weiss, D.E. Arking, M.J. Daly, A. Chakravarti, C.W. Brune, K. West, A. O'Connor, G. Hilton, R.L. Tomlinson, A.B. West, E.H. Cook Jr., T. Green, S.-. Chang, S. Gabriel, C. Gates, E.M. Hanson, A. Kirby, J. Korn, F. Kuruvilla, S. McCarroll, E.M. Morrow, B. Neale, S. Purcell, R. Sasanfar, C. Sougnez, C. Stevens, D. Altshuler, J. Gusella, S.L. Santangelo, P. Sklar, R. Tanzi, R. Anney, A.J. Bailey, G. Baird, A. Battaglia, T. Berney, C. Betancur, S. Bölte, P.F. Bolton, J. Brian, S.E. Bryson, J.D. Buxbaum, I. Cabrito, G. Cai, R.M. Cantor, H. Coon, J. Conroy, C. Correia, C. Corsello, E.L. Crawford, M.L. Cuccaro, G. Dawson, M. De Jonge, B. Devlin, E. Duketis, S. Ennis, A. Estes, P. Farrar, E. Fombonne, C.M. Freitag, L. Gallagher, D.H. Geschwind, J. Gilbert, M. Gill, C. Gillberg, J. Goldberg, A. Green, J. Green, S.J. Guter, J.L. Haines, J.F. Hallmayer, V. Hus, S.M. Klauck, O. Korvatska, J.A. Lamb, M. Laskawiec, M. Leboyer, A. Le Couteur, B.L. Leventha, X.-. Liu, C. Lord, L.J. Lotspeich, E. Maestrini, T. Magalhaes, W. Mahoney, C. Mantoulan, H. McConachie, C.J. McDougle, W.M. McMahon, C.R. Marshall, J. Miller, N.J. Minshew, A.P. Monaco, J. Munson, J.I. Nurnberger Jr., G. Oliveira, A. Pagnamenta, K. Papanikolaou, J.R. Parr, A.D. Paterson, M.A. Pericak-Vance, A. Pickles, D. Pinto, J. Piven, D.J. Posey, A. Poustka, F. Poustka, R. Regan, J. Reichert, K. Renshaw, W. Roberts, B. Roge, M.L. Rutter, J. Salt, G.D. 
Schellenberg, S.W. Scherer, V. Sheffield, J.S. Sutcliffe, P. Szatmari, K. Tansey, A.P. Thompson, J. Tsiantis, H. Van Engeland, A.M. Vicente, V.J. Vieland, F. Volkmar, S. Wallace, T.H. Wassink, E.M. Wijsman, K. Wing, K. Wittemeyer, B.L. Yaspan, L. Zwaigenbaum, S.-. Yoo, R.S. Hill, N.M. Mukaddes, S. Balkhy, G. Gascon, S. Al-Saad, A. Hashmi, J. Ware, R.M. Joseph, E. LeClair, J.N. Partlow, B. Barry, C.A. Walsh, D. Pauls, I. Moilanen, H. Ebeling, M.-. Mattila, S. Kuusikko, K Jussila, J. Ignatius, A. Tolouei, M. Ghadami, M. Rostami, A. Hosseinipour, M. Valujerdi, K. Andresen, B. Winkloski, S. Haddad, L. Kunkel, Z. Kohane, T. Tran, S. Won Kong, S.B. O'Neil, R. Hundley, I. Holm, H. Peters, E. Baroni, A. Cangialose, L. Jackson, L. Albers, R. Becker, C. Bridgemohan, S. Friedman, K. Munir, R. Nazir, J. Palfrey, A. Schonwald, E. Simmons, L.A. Rappaport, J. Gauthier, L. Mottron, R. Joober, G. Rouleau, K. Rehnstrom, L. Von Wendt and L. Peltonen, A genome-wide linkage and association scan reveals novel loci for autism, Nature 461 (2009), 802-808.

[29] P. Szatmari, A.D. Paterson, L. Zwaigenbaum, W. Roberts, J. Brian, X.Q. Liu, J.B. Vincent, J.L. Skaug, A.P. Thompson, L. Senman, L. Feuk, C. Qian, S.E. Bryson, M.B. Jones, C.R. Marshall, S.W. Scherer, V.J. Vieland, C. Bartlett, L.V. Mangin, R. Goedken, A. Segre, M.A. Pericak-Vance, M.L. Cuccaro, J.R. Gilbert, H.H. Wright, R.K. Abramson, C. Betancur, T. Bourgeron, C. Gillberg, M. Leboyer, J.D. Buxbaum, K.L. Davis, E. Hollander, J.M. Silverman, J. Hallmayer, L. Lotspeich, J.S. Sutcliffe, J.L. Haines, S.E. Folstein, J. Piven, T.H. Wassink, V. Sheffield, D.H. Geschwind, M. Bucan, W.T. Brown, R.M. Cantor, J.N. Constantino, T.C. Gilliam, M. Herbert, C. Lajonchere, D.H. Ledbetter, C. Lese-Martin, J. Miller, S. Nelson, C.A. Samango-Sprouse, S. Spence, M. State, R.E. Tanzi, H. Coon, G. Dawson, B. Devlin, A. Estes, P. Flodman, L. Klei, W.M. McMahon, N. Minshew, J. Munson, E. Korvatska, P.M. Rodier, G.D. Schellenberg, M. Smith, M.A. Spence, C. Stodgell, P.G. Tepper, E.M. Wijsman, C.E. Yu, B. Roge, C. Mantoulan, K. Wittemeyer, A. Poustka, B. Felder, S.M. Klauck, C. Schuster, F. Poustka, S. Bolte, S. FeineisMatthews, E. Herbrecht, G. Schmotzer, J. Tsiantis, K. Papanikolaou, E. Maestrini, E. Bacchelli, F. Blasi, S. Carone, C. Toma, H. Van Engeland, M. de Jonge, C. Kemner, F. Koop, M. Langemeijer, C. Hijimans, W.G. Staal, G. Baird, P.F. Bolton, M.L. Rutter, E. Weisblatt, J. Green, C. Aldred, J.A. Wilkinson, A. Pickles, A. Le Couteur, T. Berney, H. McConachie, A.J. Bailey, K. Francis, G. Honeyman, A. Hutchinson, J.R. Parr, S. Wallace, A.P. Monaco, G. Barnby, K. Kobayashi, J.A. Lamb, I. Sousa, N. Sykes, E.H. Cook, S.J. Guter, B.L. Leventhal, J. Salt, C. Lord, C. Corsello, V. Hus, D.E. Weeks, F. Volkmar, M. Tauber, E. Fombonne and A. Shih, Mapping autism risk loci using genetic linkage and chromosomal rearrangements, Nat Genet 39 (2007), 319-28.

[30] K. Wang, H. Zhang, D. Ma, M. Bucan, J.T. Glessner, B.S. Abrahams, D. Salyakina, M. Imielinski, J.P. Bradfield, P.M.A. Sleiman, C.E. Kim, C. Hou, E. Frackelton, R. Chiavacci, N. Takahashi, T. Sakurai, E. Rappaport, C.M. Lajonchere, J. Munson, A. Estes, O. Korvatska, J. Piven, L.I. Sonnenblick, A.I. Alvarez Retuerto, E.I. Herman, H. Dong, T. Hutman, M. Sigman, S. Ozonoff, A. Klin, T. Owley, J.A. Sweeney, C.W. Brune, R.M. Cantor, R. Bernier, J.R. Gilbert, M.L. Cuccaro, W.M. McMahon, J. Miller, M.W. State, T.H. Wassink, H. Coon, S.E. Levy, R.T. Schultz, J.I. Nurnberger, J.L. Haines, J.S. Sutcliffe, E.H. Cook, N.J. Minshew, J.D. Buxbaum, G. Dawson, S.F.A. Grant, D.H. Geschwind, M.A. Pericak-Vance, G.D. Schellenberg and H. Hakonarson, Common genetic vari- ants on 5 p14.1 associate with autism spectrum disorders, $\mathrm{Na}$ ture 459 (2009), 528-533.

[31] M. Alarcón, B.S. Abrahams, J.L. Stone, J.A. Duvall, J.V. Perederiy, J.M. Bomar, J. Sebat, M. Wigler, C.L. Martin, D.H. Ledbetter, S.F. Nelson, R.M. Cantor and D.H. Geschwind, Linkage, Association, and Gene-Expression Analyses Identify CNTNAP2 as an Autism-Susceptibility Gene, American Journal of Human Genetics 82 (2008), 150-159.

[32] B. Bakkaloglu, B.J. O'Roak, A. Louvi, A.R. Gupta, J.F. Abelson, T.M. Morgan, K. Chawarska, A. Klin, A.G. ErcanSencicek, A.A. Stillman, G. Tanriover, B.S. Abrahams, J.A. Duvall, E.M. Robbins, D.H. Geschwind, T. Biederer, M. Gunel, R.P. Lifton and M.W. State, Molecular Cytogenetic Analysis and Resequencing of Contactin Associated ProteinLike 2 in Autism Spectrum Disorders, American Journal of Human Genetics 82 (2008), 165-173.

[33] D.E. Arking, D.J. Cutler, C.W. Brune, T.M. Teslovich, K. West, M. Ikeda, A. Rea, M. Guy, S. Lin, E.H. Cook Jr. and A. Chakravarti, A Common Genetic Variant in the Neurexin Superfamily Member CNTNAP2 Increases Familial Risk of Autism, American Journal of Human Genetics 82 (2008), 160164.

[34] C.M. Freitag, The genetics of autistic disorders and its clinical relevance: a review of the literature, Mol Psychiatry 12 (2007), $2-22$.

[35] A.M. Persico and T. Bourgeron, Searching for ways out of the autism maze: genetic, epigenetic and environmental clues, Trends in Neurosciences 29 (2006), 349-358.

[36] V.W. Hu, A. Addington and A. Hyman, Novel autism subtypedependent genetic variants are revealed by quantitative trait and subphenotype association analyses of Published GWAS Data, PLOS ONE 6 (2011).

[37] A. Sikander, S.V. Rana and K.K. Prasad, Role of serotonin in gastrointestinal motility and irritable bowel syndrome, Clinica Chimica Acta 403 (2009), 47-55.

[38] M.R. Herbert, J.P. Russo, S. Yang, J. Roohi, M. Blaxill, S.G. Kahler, L. Cremer and E. Hatchwell, Autism and environmental genomics, Neurotoxicology 27 (2006), 671-84.

[39] T. Buie, D.B. Campbell, G.J. Fuchs III, G.T. Furuta, J. Levy, J. Van De Water, A.H. Whitaker, D. Atkins, M.L. Bauman, A.L. Beaudet, E.G. Carr, M.D. Gershon, S.L. Hyman, P. Jirapinyo, H. Jyonouchi, K. Kooros, R. Kushak, P. Levitt, S.E. Levy, J.D. Lewis, K.F. Murray, M.R. Natowicz, A. Sabra, B.K. Wershil, S.C. Weston, L. Zeltzer and H. Winter, Evaluation, diagnosis, and treatment of gastrointestinal disorders in individuals with ASDs: A consensus report, Pediatrics 125 (2010), S1-S18.

[40] M. Nishimura, Y. Kuboi, K. Muramoto, T. Kawano and T. Imai, Chemokines as novel therapeutic targets for inflammatory bowel disease, Annals of the New York Academy of Sciences 1173 (2009), 350-356.

[41] Y. Tani, E. Fernell, Y. Watanabe, T. Kanai and B. Langstrom, Decrease in GR-5,6,7,8-tetrahydrobiopterin content in cerebrospinal fluid of autistic patients, Neuroscience letters $\mathbf{1 8 1}$ (1994), 169-172.

[42] R.E. Frye, L.C. Huffman and G.R. Elliott, Tetrahydrobiopterin as a novel therapeutic intervention for autism, Neurotherapeutics 7 (2010), 241-249.

[43] V.W. Hu, A systems approach towards an understanding, diagnosis and personalized treatment of autism spectrum disorders, Pharmacogenomics 12 (2011), 1235-1238.

[44] J.C. Chuang and P.A. Jones, Epigenetics and microRNAs, Pediatr Res 61 (2007), 24R-29R.

[45] J. Hsieh and A.J. Eisch, Epigenetics, hippocampal neurogenesis, and neuropsychiatric disorders: Unraveling the genome 
to understand the mind, Neurobiology of disease 39 (2010), 73-84.

[46] J. Feng and G. Fan, The Role of DNA Methylation in the Central Nervous System and Neuropsychiatric Disorders, International Review of Neurobiology 89 (2009), 67-84.

[47] S. Martino, I. Di Girolamo, A. Orlacchio, A. Datti and A. Orlacchio, MicroRNA implications across neurodevelopment and neuropathology, Journal of Biomedicine and Biotechnology 2009 (2009)

[48] J. Mill, T. Tang, Z. Kaminsky, T. Khare, S. Yazdanpanah, L. Bouchard, P. Jia, A. Assadzadeh, J. Flanagan, A. Schumacher, S.-. Wang and A. Petronis, Epigenomic Profiling Reveals DNA-Methylation Changes Associated with Major Psychosis, American Journal of Human Genetics 82 (2008), 696-711.

[49] T. Kerin, A. Ramanathan, K. Rivas, N. Grepo, G.W. Coetzee and D.B. Campbell, A noncoding RNA antisense to moesin at 5p14.1 in autism, Science Translational Medicine 4 (2012), 1.

[50] T.W. Nilsen, Mechanisms of microRNA-mediated gene regulation in animal cells, Trends in Genetics 23 (2007), 243-249.

[51] S. Bicker and G. Schratt, microRNAs: Tiny regulators of synapse function in development and disease, Journal of Cellular and Molecular Medicine 12 (2008), 1466-1476.

[52] R. Fiore, G. Siegel and G. Schratt, MicroRNA function in neuronal development, plasticity and disease, Biochimica et Biophysica Acta - Gene Regulatory Mechanisms 1779 (2008), 471-478.

[53] M. Kapsimali, W.P. Kloosterman, E. de Bruijn, F. Rosa, R.H. Plasterk and S.W. Wilson, MicroRNAs show a wide diversity of expression profiles in the developing and mature central nervous system, Genome Biol 8 (2007), R173.

[54] K.S. Kosik, The neuronal microRNA system, Nat Rev Neurosci 7 (2006), 911-20.

[55] K. Abu-Elneel, T. Liu, F.S. Gazzaniga, Y. Nishimura, D.P. Wall, D.H. Geschwind, K. Lao and K.S. Kosik, Heterogeneous dysregulation of microRNAs across the autism spectrum, $\mathrm{Neu}$ rogenetics 9 (2008), 153-161.

[56] Z. Talebizadeh, M.G. Butler and M.F. Theodoro, Feasibility and relevance of examining lymphoblastoid cell lines to study role of microRNAs in autism, Autism Research 1 (2008), 307.

[57] T. Sarachana, R. Zhou, G. Chen, H.K. Manji and V.W. $\mathrm{Hu}$, Investigation of post-transcriptional gene regulatory networks associated with autism spectrum disorders by microRNA expression profiling of lymphoblastoid cell lines, Genome medicine 2 (2010), 23

[58] L.F. Sempere, S. Freemantle, I. Pitha-Rowe, E. Moss, E. Dmitrovsky and V. Ambros, Expression profiling of mammalian microRNAs uncovers a subset of brain-expressed microRNAs with possible roles in murine and human neuronal differentiation, Genome Biol 5 (2004), R13.

[59] A.M. Krichevsky, K.S. King, C.P. Donahue, K. Khrapko and K.S. Kosik, A microRNA array reveals extensive regulation of microRNAs during brain development, RNA 9 (2003), 12741281.

[60] Y. Liang, D. Ridzon, L. Wong and C. Chen, Characterization of microRNA expression profiles in normal human tissues, BMC Genomics 8 (2007).

[61] A. Schaefer, D. O'Carroll, L.T. Chan, D. Hillman, M. Sugimori, R. Llinas and P. Greengard, Cerebellar neurodegeneration in the absence of microRNAs, Journal of Experimental Medicine 204 (2007), 1553-1558.

[62] S. Jung, R.-. Park, S. Kim, Y.-. Jeon, D.-. Ham, M.-. Jung, S.-. Kim, Y.-. Lee, C.-. Park and H. Suh-Kim, Id proteins facilitate self-renewal and proliferation of neural stem cells, Stem Cells and Development 19 (2010), 831-841.
[63] A. Jogi, P. Persson, A. Grvnfeld, S. Pahlman and H. Axelson, Modulation of basic helix-loop-helix transcription complex formation by Id proteins during neuronal differentiation, J Biol Chem 277 (2002), 9118-9126.

[64] C. Draghetti, C. Salvat, F. Zanoguera, M.-. Curchod, C. Vignaud, H. Peixoto, A. Di Cara, D. Fischer, M. Dhanabal, G. Andreas, H. Abderrahim, C. Rommel and M. Camps, Functional whole-genome analysis identifies polo-like kinase 2 and poliovirus receptor as essential for neuronal differentiation upstream of the negative regulator $\alpha \mathrm{B}$-crystallin, Journal of Biological Chemistry 284 (2009), 32053-32065.

[65] K. Lee, Y. Lee, A. Rozeboom, J.-. Lee, N. Udagawa, H.-. Hoe and D. Pak, Requirement for Plk2 in Orchestrated Ras and Rap Signaling, Homeostatic Structural Plasticity, and Memory, Neuron 69 (2011), 957-973.

[66] M.M. Ghahramani Seno, P. Hu, F.G. Gwadry, D. Pinto, C.R. Marshall, G. Casallo and S.W. Scherer, Gene and miRNA expression profiles in autism spectrum disorders, Brain research 1380 (2011), 85-97.

[67] E.M. Kroh, R.K. Parkin, P.S. Mitchell and M. Tewari, Analysis of circulating microRNA biomarkers in plasma and serum using quantitative reverse transcription-PCR (qRT-PCR), Methods $\mathbf{5 0}$ (2010), 298-301.

[68] P.S. Mitchell, R.K. Parkin, E.M. Kroh, B.R. Fritz, S.K. Wyman, E.L. Pogosova-Agadjanyan, A. Peterson, J. Noteboom, K.C. O'Briant, A. Allen, D.W. Lin, N. Urban, C.W. Drescher, B.S. Knudsen, D.L. Stirewalt, R. Gentleman, R.L. Vessella, P.S. Nelson, D.B. Martin and M. Tewari, Circulating microRNAs as stable blood-based markers for cancer detection, Proceedings of the National Academy of Sciences of the United States of America 105 (2008), 10513-10518.

[69] D. Grafodatskaya, B. Chung, P. Szatmari and R. Weksberg, Autism Spectrum Disorders and Epigenetics, Journal of the American Academy of Child and Adolescent Psychiatry (2010).

[70] A. Nguyen, T.A. Rauch, G.P. Pfeifer and V.W. Hu, Global methylation profiling of lymphoblastoid cell lines reveals epigenetic contributions to autism spectrum disorders and a novel autism candidate gene, RORA, whose protein product is reduced in autistic brain, The FASEB Journal: Official Publication of the Federation of American Societies for Experimental Biology 24 (2010), 3036-3051.

[71] V.W. Hu, B.C. Frank, S. Heine, N.H. Lee and J. Quackenbush, Gene expression profiling of lymphoblastoid cell lines from monozygotic twins discordant in severity of autism reveals differential regulation of neurologically relevant genes, $B M C$ Genomics 7 (2006), 118.

[72] V.W. Hu, A. Nguyen, K.S. Kim, M.E. Steinberg, T. Sarachana, M.A. Scully, S.J. Soldin, T. Luu and N.H. Lee, Gene expression profiling of lymphoblasts from autistic and nonaffected sib pairs: altered pathways in neuronal development and steroid biosynthesis, PloS one 4 (2009), e5775.

[73] S.H. Fatemi, J.M. Stary, A.R. Halt and G.R. Realmuto, Dysregulation of Reelin and Bcl-2 proteins in autistic cerebellum, J Autism Dev Disord 31 (2001), 529-35.

[74] S.H. Fatemi and A.R. Halt, Altered levels of Bcl2 and p53 proteins in parietal cortex reflect deranged apoptotic regulation in autism, Synapse 42 (2001), 281-4.

[75] D.A. Gold, P.M. Gent and B.A. Hamilton, ROR $\alpha$ in genetic control of cerebellum development: 50 staggering years, Brain research 1140 (2007), 19-25.

[76] H.P. Harding, G.B. Atkins, A.B. Jaffe, W.J. Seo and M.A. Lazar, Transcriptional activation and repression by $\operatorname{ROR} \alpha$, an 
orphan nuclear receptor required for cerebellar development, Molecular Endocrinology 11 (1997), 1737-1746.

[77] F. Boukhtouche, M. Doulazmi, F. Frederic, I. Dusart, B. Brugg and J. Mariani, $\operatorname{ROR} \alpha$, a pivotal nuclear receptor for Purkinje neuron survival and differentiation: From development to ageing, Cerebellum 5 (2006), 97-104.

[78] F. Boukhtouche, G. Vodjdani, C.I. Jarvis, J. Bakouche, B. Staels, J. Mallet, J. Mariani, Y. Lemaigre-Dubreuil and B. Brugg, Human retinoic acid receptor-related orphan receptor $\alpha 1$ overexpression protects neurones against oxidative stressinduced apoptosis, Journal of Neurochemistry 96 (2006), 1778-1789.

[79] P. Delerive, D. Monteì, G. Dubois, F. Trottein, J. FruchartNajib, J. Mariani, J.-. Fruchart and B. Staels, The orphan nuclear receptor $\mathrm{ROR} \alpha$ is a negative regulator of the inflammatory response, EMBO reports 2 (2001), 42-48.

[80] F. Sato, T. Kawamoto, K. Fujimoto, M. Noshiro, K.K. Honda, S. Honma, K.-. Honma and Y. Kato, Functional analysis of the basic helix-loop-helix transcription factor DEC1 in circadian regulation: Interaction with BMAL1, European Journal of Biochemistry 271 (2004), 4409-4419.

[81] R. Lalonde and C. Strazielle, Discrimination learning in Rorasg and Grid2ho mutant mice, Neurobiology of learning and memory 90 (2008), 472-474.

[82] G. Goodall and G. Gheusi, Abnormal patterns of maze patrolling in the mutant mouse staggerer, Behavioral and neural biology 47 (1987), 307-320.

[83] R. Lalonde, M.I. Botez and D. Boivin, Object exploration in staggerer mutant mice, Physiology and Behavior 41 (1987), 115-117.

[84] R. Lalonde, Exploration and spatial learning in staggerer mutant mice, Journal of neurogenetics 4 (1987), 285-292.

[85] M. Doulazmi, F. Frédéric, Y. Lemaigre-Dubreuil, N. HadjSahraoui, N. Delhaye-Bouchaud and J. Mariani, Cerebellar Purkinje cell loss during life span of the heterozygous staggerer mouse (Rora+/Rora(sg)) is gender-related, Journal of Comparative Neurology 411 (1999), 267-273.

[86] T. Sarachana, M. Xu, R.-C. Wu and V.W. Hu, Sex hormones in autism: Androgens and estrogens differentially and reciprocally regulate RORA, a novel candidate gene for autism, PLoS ONE 6 (2011), e17116.

[87] R.C. Knickmeyer and S. Baron-Cohen, Fetal testosterone and sex differences in typical social development and in autism, $J$ Child Neurol 21 (2006), 825-45.

[88] E. Ingudomnukul, S. Baron-Cohen, S. Wheelwright and R. Knickmeyer, Elevated rates of testosterone-related disorders in women with autism spectrum conditions, Horm Behav $\mathbf{5 1}$ (2007), 597-604.

[89] B. Auyeung, S. Baron-Cohen, E. Ashwin, R. Knickmeyer, K. Taylor and G. Hackett, Fetal testosterone and autistic traits, British Journal of Psychology 100 (2009), 1-22.

[90] L.R. Chura, M.V. Lombardo, E. Ashwin, B. Auyeung, B. Chakrabarti, E.T. Bullmore and S. Baron-Cohen, Organizational effects of fetal testosterone on human corpus callosum size and asymmetry, Psychoneuroendocrinology 35 (2010), 122-132. 


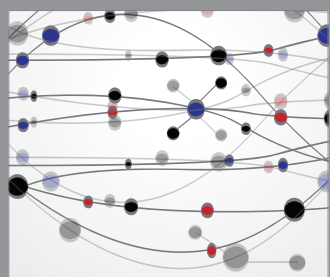

The Scientific World Journal
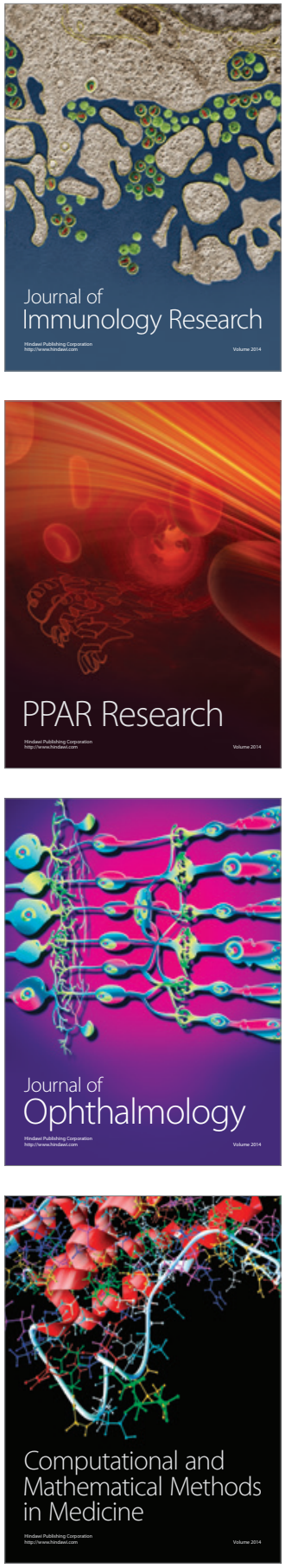

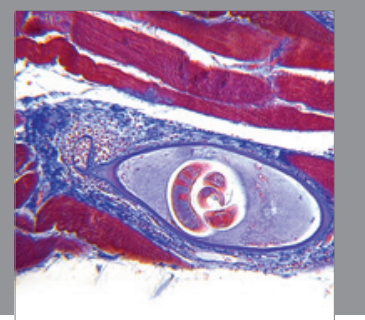

Gastroenterology

Research and Practice
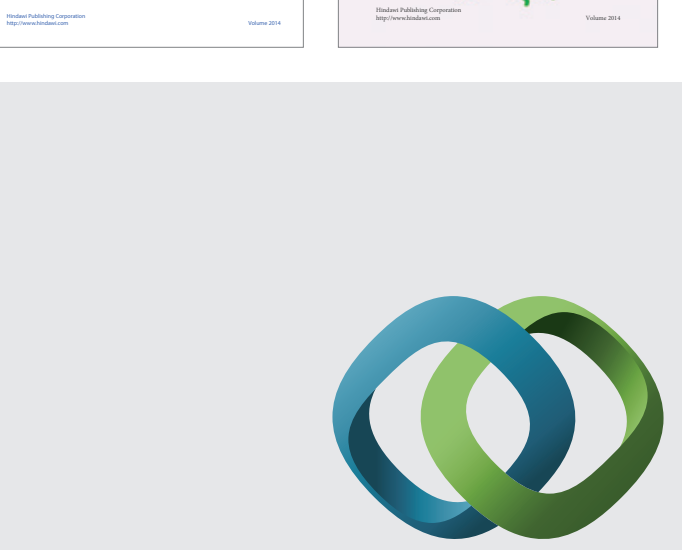

\section{Hindawi}

Submit your manuscripts at

http://www.hindawi.com
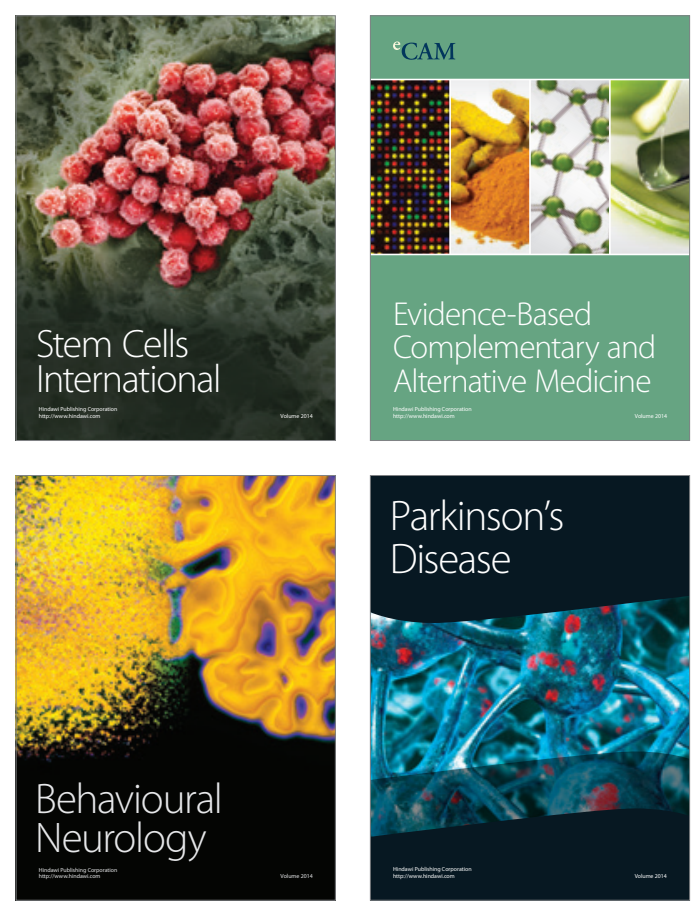

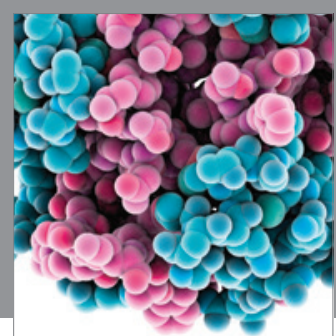

Journal of
Diabetes Research

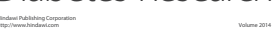

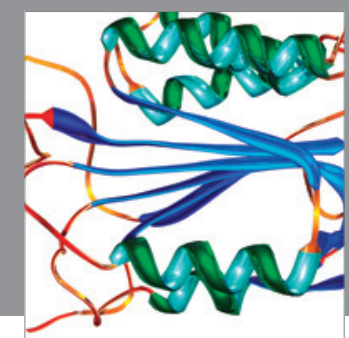

Disease Markers
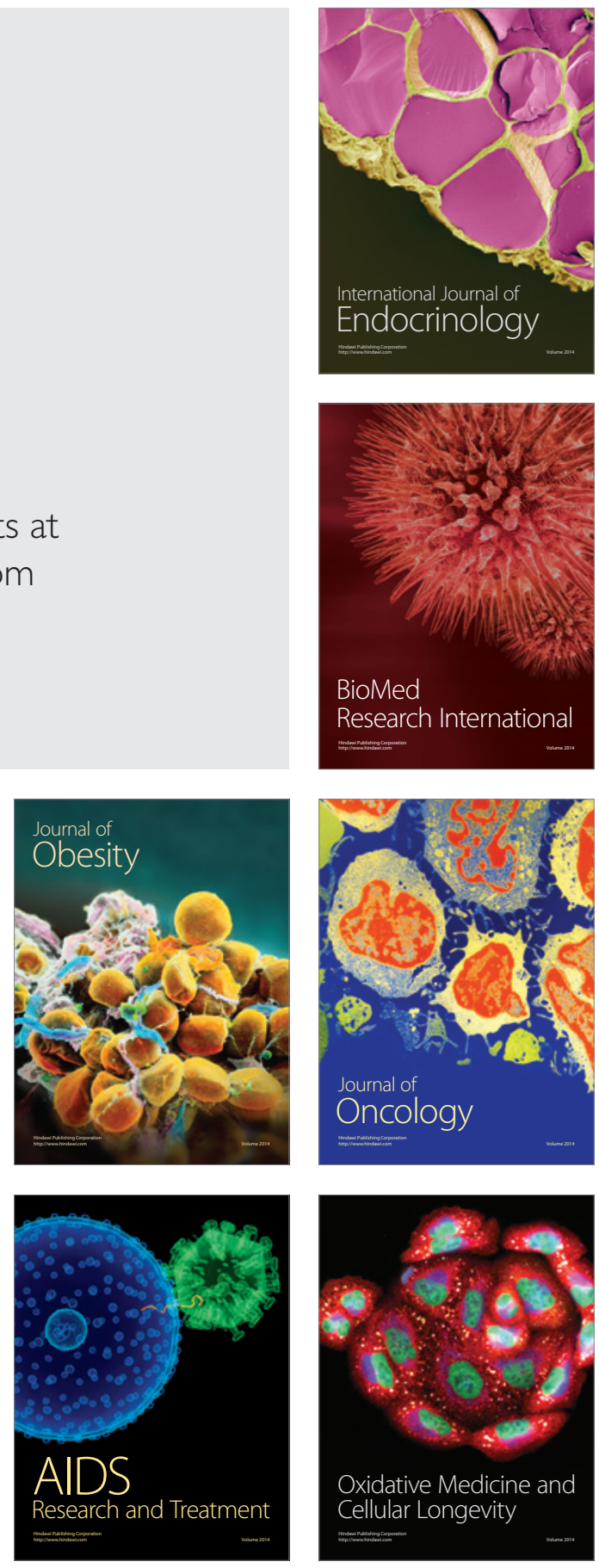